\title{
Environmental Policy and Speculation on markets for emission permits
}

P. Colla, M. Germain and V. Van Steenberghe

Discussion Paper 2005-49

Département des Sciences Économiques

de l'Université catholique de Louvain 


\title{
Environmental policy and speculation on markets for emission permits*
}

\author{
Paolo Colla ${ }^{\dagger} \quad$ Marc Germain ${ }^{\ddagger} \quad$ Vincent van Steenberghe ${ }^{\S}$
}

October 2005

\begin{abstract}
Tradable emission permits share many characteristics with financial assets. As on financial markets, speculators are likely to be active on large markets for emission permits such as those developing under the Kyoto Protocol. We show how the presence of speculators on a market for emission permits affects the price of these permits when firms face risk aversion. The agency in charge of the optimal environmental policy should account for the presence of speculators when determining the total amount of permits to issue.
\end{abstract}

${ }^{*}$ The authors wish to thank Parkash Chander, Jacques Drèze, Alphonse Magnus, Enrico Minelli and Bert Willems for fruitful discussions. Financial support from the Belgian Scientific Policy (contract CLIMNEG2) is gratefully acknowleged.

${ }^{\dagger}$ Università Bocconi (paolo.colla@unibocconi.it).

${ }^{\ddagger}$ CORE and Département d’Economie, Université catholique de Louvain (germain@core.ucl.ac.be).

${ }^{\S}$ Belgian National Fund for Scientific Research (FNRS) and CORE, Université catholique de Louvain (vansteenberghe@core.ucl.ac.be). 


\section{Introduction}

The interest in markets for emission permits has increased worldwide after the signature of the Kyoto Protocol in December 1997. Although emission constraints will only be binding from 2008 onwards, the embedded so-called "flexible mechanisms" for reducing greenhouse gas emissions are already giving rise to the largest markets for emission permits. The European market for carbon dioxide emission permits -launched in January 2005- as well as other national or regional initiatives, are paving the way towards a global market. Moreover, the implementation of emission permits markets is currently under development or consideration for the control of other air pollutants (such as $\mathrm{SO}_{2}, \mathrm{NOx}, \mathrm{VOC}$, etc.) in numerous countries (see e.g. Stavins (2003)). The design of most of these schemes is inspired by the American experiences with such markets, especially the Acid Rain Program.

Emission permits share many characteristics with financial assets. An emission permit (also often called 'allowance') allows a regulated agent to emit a specified amount of a certain pollutant during a given period of time (e.g. 1 ton of sulfur dioxide or carbon dioxide in the year 2005). The permits are virtual assets: an agent holds a permit if this permit is registered on the account of that agent by the environmental agency. Hence, emission permits are perfect substitutes and their trade entails neither transportation nor inventory costs. Such characteristics are favorable to the entry on the market of other agents than regulated polluters, typically speculators.

Analyses of the US Acid Rain Program (see e.g. Schmalensee et al. (1998)) or of the emerging European market for carbon dioxide emission permits (see e.g. Convery and Ruthmond (2005)) reveal the presence of such agents on these markets. In fact, numerous financial institutions are active on the European market and hedge funds are expected to enter soon. At present, the number of market participants is already very large and expected to sharply increase when all permits accounts become operational in the Eastern European countries. Moreover, although permits are currently traded at different places, market analysts forecast that trades will soon be performed on an unique centralized exchange. This would increase the transparency of the market and ease the access to it. Since, in addition, it is particularly simple to open a permits account by the environmental agency ${ }^{1}$, the number of players other than regulated firms is likely to be very large.

Nevertheless, to our knowledge, the literature on the tradable emission permits instrument has so far ignored the possible presence of these agents. Although they focus on the microstructure on markets for emission permits, the contributions by Germain et al. (2004a,b) analyze only the role of intermediaries and show how a price-driven market may lead to a strictly positive spread. They leave aside the issue of speculation.

\footnotetext{
${ }^{1}$ Agents can manage their accounts via the internet, just like for internet banking.
} 
Analyzing speculation on markets for emission permits is particularly relevant because speculators may have an impact on the equilibrium permits price and, consequently, on firms' investment/production choices. Speculators stand ready to accommodate the excess demand of permits stemming from firms. As such speculators serve as market makers for pollution permits, and the equilibrium price therefore includes a premium for holding inventories firms are willing to unload. ${ }^{2}$ Such a change in the price signal would in turn affect firms investment and production decisions. When the environmental agency balances the environmental quality with the cost for the firms of reducing pollution, it should account for the impact of speculators.

In terms of methodology, we introduce risk averse polluting firms which have to decide on the amount of capital (or abatement) under uncertainty. This is similar to the approach followed by Baldursson and von der Fehr (2003) who analyze the consequences of price volatility on permits markets. ${ }^{3}$ We make the additional assumption of constant absolute risk aversion in order to get closed form solutions and enrich the framework in three directions: we account for repeated permits trading rounds, we introduce risk averse speculators and we compute the optimal amount of emission permits to be issued by the environmental agency.

The main results of our paper are related to these aspects as follows. The uncertainty firms face when choosing their level of capital makes them willing to sell (part of) their emission permits during the first trading round. Once uncertainty is resolved and capital has been allocated, firms purchase back the permits at the second round. Speculators hold positive inventories of permits between the two dates and earn positive expected returns as compensation for their risk bearing activity. The analysis reveals that social welfare changes with the risk bearing capacity of the market, which in turn depends on the market participants' risk attitude.

The paper is organized as follows. In Section 1, we present firms and speculators characteristics and we outline the sequence of decisions. The permits market equilibrium is then analyzed. Section 2 is devoted to the policy pursued by the environmental agency. Its role is to determine the optimal amount of emission permits to be issued. We also analyze the impact of changes in the risk bearing capacity of the market on expected social welfare. Key results of the analysis, as well as short-selling constraints and the introduction of derivatives, are further discussed in Section 3. Finally,

\footnotetext{
${ }^{2}$ In a different context, Bernardo and Welch (2004) consider the interaction between a pool of investors facing potential liquidity shocks and a sector of speculators absorbing unwanted inventories.

${ }^{3}$ Baldursson and von der Fehr (2003) address the issue of how the introduction of risk aversion by firms affects the performance of the tradable permits instrument w.r.t. the tax instrument. Among other things, they show that accounting for risk aversion tends to increase the relative performance of taxes.
} 
in Section 4 we summarize our results and present possible extensions to the current analysis.

\section{The model}

\subsection{Preliminaries: the agents}

We shall consider three types of agents: firms, speculators and an environmental agency. The agency is in charge of defining a total amount of emission permits and of (freely) allocating them to firms. We assume for the time being that the agency has already defined a total amount of permits denoted by $S_{0}$. The behavior of the agency, leading to the definition of the optimal amount of permits by taking into account the damage costs due to emissions of pollutants, is analyzed in section 2. Let us now describe firms and speculators, assuming that there is a continuum of each of them, with $\lambda \in(0,1)$ (resp. $1-\lambda)$ being the share of speculators (resp. firms).

\subsubsection{Firms}

Each firm, indexed by $i$, produces the good $y$ whose price is normalized to 1 . All firms have the same Cobb-Douglas constant returns to scale production function:

$$
y_{i}=\theta k_{i}^{\alpha} e_{i}^{1-\alpha} \quad \text { with } 0<\alpha<1
$$

where $k_{i}$ denotes the level of capital employed by firm $i$ and $e_{i}$ is the amount of emissions used by the same firm. The parameter $\theta$ represents a shock on the production function of the firms. ${ }^{4}$ This shock affects all firms in the same way and is normally distributed with mean $\mu>0$ and variance $\sigma^{2} .^{5}$

Firms purchase capital at the exogenous price $r>0$. Moreover, when a firm emits pollutants, it must hold an amount of permits which is not lower than the level of emissions. Each firm freely receives from the environmental agency $^{6}$ an amount of emission permits $s_{i 0}$ and may sell some of them to -or purchase some additional ones from- other agents. Such trades may take place at any moment after permits have been allocated. For simplicity, we assume that the market for permits opens at two different trading periods

\footnotetext{
${ }^{4}$ This shock is modelled as a change in the productivity of the firms. However, its interpretation is broader than that. For instance, since the output price is given (and normalized to 1), $y_{i}$ can be interpreted as firm $i$ sales revenues. In this case, a change in $\theta$ could represent a change in such revenues due to a change in the output price, resulting itself from a change in the demand for that output.

${ }^{5}$ Under this normality assumption, the technology parameter -and consequently revenues from product sales- might take negative values. However -as noted by Vives (1984)one can make the probability of negative prices (or output) arbitrarily small by choosing high values for $\mu$ and low values for $\sigma^{2}$.

${ }^{6}$ The way permits are shared among firms is irrelevant and it does not play any role in the model solution, as will become clear in the remainder.
} 
indexed by $t(t=1,2)$. The unit price of permits on the market is then denoted by $p_{t}$.

Given this notation, the profit of firm $i$ reads as follows:

$$
\pi_{F i}=\pi_{F}\left(k_{i}, s_{i 1}, e_{i} ; \theta\right)=\theta k_{i}^{\alpha} e_{i}^{1-\alpha}-r k_{i}-p_{1}\left(s_{i 1}-s_{i 0}\right)-p_{2}\left(s_{i 2}-s_{i 1}\right)
$$

where $s_{i 0}$ is the amount of emission permits freely allocated to firm $i$ and $s_{i t}(t=1,2)$ is the amount of permits held by firm $i$ at the end of trading period $t$, i.e. firm $i$ 's inventory of permits at period $t$. Therefore firm $i$ purchases (resp. sells) permits at the trading round $t$ if $s_{i t}-s_{i t-1}>0$ (resp. $\left.s_{i t}-s_{i t-1}<0\right)$.

Each firm's total profit is composed of the revenues from the sales of the product, $y_{i}$, the cost of capital and the cost (resp. benefits) of the net permits purchases (resp. sales). As long as permits prices are strictly positive $^{7}$, the requirement that each firm must hold an amount of permits greater or equal to its emissions level $\left(s_{i 2} \geq e_{i}\right)$ will hold with equality, and we set $s_{i 2}=e_{i}$ in eq. (1).

Firms are risk-averse as captured by a constant-absolute risk-aversion (CARA) function defined over their profits, and we let $\gamma_{F}>0$ denote the risk-aversion parameter supposed to be identical for all firms.

\subsubsection{Speculators}

Besides firms, speculators are active on the market for emission permits. We consider a continuum of identical speculators indexed by $j$ and of measure $\lambda$. Unlike firms, speculators do not produce or pollute and their profits result from their trading activity only. We assume that speculators have no initial endowments of permits (i.e., all permits issued by the agency are allocated to firms). Therefore speculators profit from the price difference between the two trading periods, i.e., by purchasing (or short-selling) permits in the first trading period and unwinding their position during the second trading round. Hence their profit function is given by

$$
\pi_{S j}=\pi_{S}\left(x_{j t} ; \theta\right)=-p_{2} x_{j 2}-p_{1} x_{j 1}
$$

where $x_{j t}$ is the purchase $\left(x_{j t}>0\right)$ or sale $\left(x_{j t}<0\right)$ of permits in trading period $t$, subject to $x_{j 1}+x_{j 2} \geq 0$, i.e. speculators should hold non-negative inventories in the last period. As long as permits prices are strictly positive, speculators will set $x_{j 2}=-x_{j 1}$.

We assume that speculators are also risk-averse with CARA utility function defined over final profits $\pi_{S j}$ and denote by $\gamma_{S}>0$ their degree of risk aversion.

\footnotetext{
${ }^{7}$ Which will be the case hereafter (see footnote 8 hereafter).
} 


\subsubsection{Timing}

The sequence of decisions is as follows. In period 0 , the agency issues and allocates to firms the total amount of permits $S_{0}=\int_{0}^{1-\lambda} s_{i 0} d i$. All agents face uncertainty on the technology parameter $\theta$. In period 1 , firms choose their amount of capital, $k_{i}$, and set their emission permits inventory level, $s_{i 1}$. At the same time, speculators may also trade permits, $x_{j 1}$. Then, the value of $\theta$ is revealed to all agents. In period 2, firms decide on their amount of emissions, $e_{i}$, and trade permits, $e_{i}-s_{i 1}$. Speculators unwind their time 1 position trading $-x_{j 1}$. This sequence of decisions is illustrated in Figure 1.

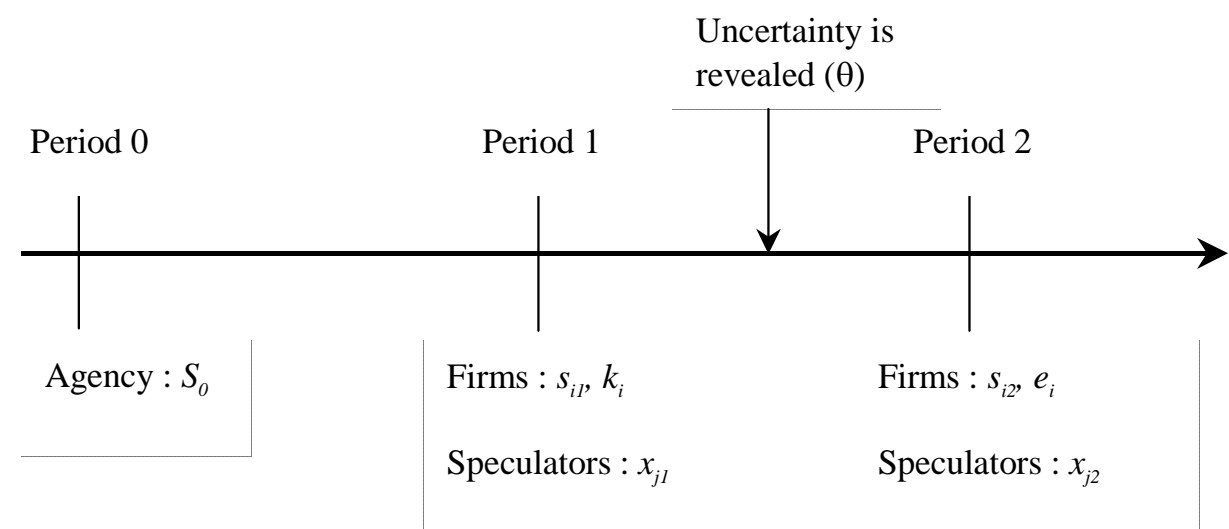

Figure 1: Sequence of decisions

Let us now move to the solution of the model, starting with the second trading round.

\subsection{The market for emission permits at time 2}

At time $t=2$ there is no uncertainty on the technology parameter $\theta$, and each firm maximizes profits with respect to the level of emissions given its first period choices, i.e.:

$$
\max _{e_{i}} \pi_{F}\left(k_{i}, s_{i 1}, e_{i} ; \theta\right)
$$

given $k_{i}, s_{i 1}$, with $\pi_{F}(\cdot)$ as in eq. (1). The first order condition gives the demand schedule for permits chosen by the firm:

$$
e_{i}\left(p_{2}\right)=\left[\frac{(1-\alpha) \theta}{p_{2}}\right]^{\frac{1}{\alpha}} k_{i} .
$$

Firm $i$ net demand for permits is then given by $e_{i}-s_{i 1}$. At time 2 , speculators unwind their date 1 position in the permits, ending up with null inventories 
at the second trading round, i.e. $x_{j 2}=-x_{j 1}$, where $x_{j 1}$ is chosen in period 1.

Accordingly, the permits market clearing condition in period 2 reads as follows:

$$
\int_{0}^{1-\lambda}\left(e_{i}\left(p_{2}\right)-s_{i 1}\right) d i+\int_{0}^{\lambda}-x_{j 1} d j=0 .
$$

or equivalently $\int_{0}^{1-\lambda} e_{i}\left(p_{2}\right) d i=\int_{0}^{1-\lambda} s_{i 1} d i+\int_{0}^{\lambda} x_{j 1} d j$, i.e. firms' emissions are equal to the stock of permits held by firms and speculators after the first trading round. As is clear, this stock must be equal to the amount of permits the agency distributes to firms at time 0 , such that eq. (4) reduces to $\int_{0}^{1-\lambda} e_{i}\left(p_{2}\right) d i=S_{0}$. Using the latter condition and (3), we obtain the second period permits price:

$$
p_{2}=\frac{1-\alpha}{\Delta^{\alpha}} \theta
$$

where $\Delta \equiv \frac{S_{0}}{K}$ and $K$ denotes the aggregate level of capital, i.e. $K=$ $\int_{0}^{1-\lambda} k_{i} d i{ }^{8}$ Therefore in equilibrium, firms emissions are given by

$$
e_{i}=\Delta k_{i}
$$

\subsection{The market for emission permits at time 1}

\subsubsection{Firms}

At time $t=1$, all agents face uncertainty about the productivity level prevailing at date 2 in the economy. Each firm solves $\max _{k_{i}, s_{i 1}} E\left(u_{F}\left(\pi_{F i}\right)\right)$ subject to (5) and (6), where $u_{F}(\cdot)$ denotes firm $i$ 's utility function. Substituting the equilibrium values for $e_{i}$ and $p_{2}$ into the expression for $\pi_{F i}$ as given by (1) yields:

$$
\pi_{F i}=\pi_{F}\left(k_{i}, s_{i 1} ; \theta\right)=\frac{\theta}{\Delta^{\alpha}}\left(\alpha \Delta k_{i}+(1-\alpha) s_{i 1}\right)-r k_{i}-p_{1}\left(s_{i 1}-s_{i 0}\right) .
$$

Recall that the technology parameter $\theta$ is assumed to be normally distributed with mean $\mu$ and variance $\sigma^{2}$, implying that profits are also normally distributed. As is known (see for example Lintner (1969)), optimization of a CARA utility function defined over a normal random variable allows to write firm $i$ maximization problem as

$$
\max _{k_{i}, s_{i 1}} E\left(u_{F}\left(\pi_{F i}\right)\right)=\max _{k_{i}, s_{i 1}} \mu_{F}\left(k_{i}, s_{i 1}\right)-\frac{\gamma_{F}}{2} \sigma_{F}^{2}\left(k_{i}, s_{i 1}\right)
$$

where $\mu_{F}(\cdot)$ and $\sigma_{F}^{2}(\cdot)$ denote respectively the mean and the variance of firm $i$ 's profits. Although firms are price taker and face constant returns to scale,

\footnotetext{
${ }^{8}$ Given that $\theta$ is normally distributed, $p_{2}$ could in principle be negative. However, as mentioned earlier in the paper, we assume that $\mu$ (resp. $\left.\sigma^{2}\right)$ is sufficiently high (resp. low) so that the probability of such a situation can be neglected.
} 
one must note that this problem has an interior solution since uncertainty and risk aversion make the expected utility of firms a concave function in its arguments (on this topic, see Sandmo (1971)).

The first order conditions of the problem lead to:

$$
\begin{aligned}
k_{i} & =\frac{\alpha p_{1}}{(1-\alpha) r} \frac{S_{0}}{1-\lambda} \\
s_{i 1} & =\frac{\Delta^{2 \alpha}}{\gamma_{F} \sigma^{2}(1-\alpha)^{2}}\left(\frac{(1-\alpha)}{\Delta^{\alpha}} \mu-p_{1}\right)-\frac{r k_{i}}{p_{1}} .
\end{aligned}
$$

where

$$
\Delta=\frac{(1-\alpha) r}{\alpha p_{1}}
$$

The demand of capital and permits are identical for all firms since they have the same technology and risk aversion. These conditions can be interpreted as follows. Relation (8) means that the optimal amount of capital chosen by the firms is an increasing function of the total amount of permits allocated $\left(S_{0}\right)$, a decreasing function of its price $(r)$ and an increasing function of the price of the other input $\left(p_{1}\right)$. Relation (9) shows that the amount of permits held by firm $i$ in period 1 is a decreasing function of its level of capital. We will come back to its interpretation in the following section.

At the aggregate level, since there is a continuum of firms of measure $1-\lambda$, the total amount of capital is

$$
K=(1-\lambda) k_{i}=\frac{\alpha p_{1}}{(1-\alpha) r} S_{0}
$$

\subsubsection{Speculators}

The speculators' problem is defined along the same lines as for firms. Each speculator solves $\max _{x_{j 1}} E\left(u_{S}\left(\pi_{S j}\right)\right)$, where $u_{S}(\cdot)$ denotes speculator $j$ 's utility function. Since all speculators are identical, $x_{j 1}=x_{1}$ for all $j \in[0, \lambda]$ and we drop the subscript $j$ in the remainder. Given the equilibrium price $p_{2}$ (see eq. (5)), profits $\pi_{S}$ as defined by relation (2) are normal with first two moments $\mu_{S}(\cdot)$ and $\sigma_{S}^{2}(\cdot)$. The maximization problem becomes

$$
\max _{x_{1}} \mu_{S}\left(x_{1}\right)-\frac{\gamma_{S}}{2} \sigma_{S}^{2}\left(x_{1}\right)
$$

and the optimal demand (or inventory) of each speculator is then

$$
x_{1}=\frac{\Delta^{2 \alpha}}{\gamma_{S} \sigma^{2}(1-\alpha)^{2}}\left(\frac{(1-\alpha)}{\Delta^{\alpha}} \mu-p_{1}\right) .
$$

It follows that first period firms' inventories in (9) can be rewritten as

$$
s_{i 1}=\gamma x_{1}-\frac{r K}{p_{1}(1-\lambda)}
$$


where $\gamma=\gamma_{S} / \gamma_{F}$ denotes the ratio between risk-aversion coefficients. The first RHS term relates to their trading activity, i.e., buying (selling) permits in period 1 in order to gain by selling (purchasing) them at a higher (lower) price in period 2. The second RHS term corresponds to the amount of permits the firm decides to hold in order to be allowed to emit pollution. This term is negatively related to the amount of capital it holds.

\subsubsection{Market equilibrium}

The first period market clearing condition is:

$$
\int_{0}^{1-\lambda}\left(s_{i 1}\left(p_{1}\right)-s_{i 0}\right) d i+\int_{0}^{\lambda} x_{j 1}\left(p_{1}\right) d j=0
$$

Using relations (9-12), and letting $A=\frac{(1-\alpha) r}{\alpha}$ and $B=\sigma^{2}\left(\frac{1-\lambda}{\gamma_{F}}+\frac{\lambda}{\gamma_{S}}\right)^{-1}$ the first period permits price solves the following implicit function:

$$
A^{2 \alpha} p_{1}^{1-\alpha}+(1-\alpha) B S_{0} p_{1}^{\alpha}-(1-\alpha) A^{\alpha} \mu=0 .
$$

Equation (14) does not allow to explicitly compute the equilibrium price $p_{1}^{*}=p_{1}\left(\alpha, \mu, A, B, S_{0}\right)$. However, the existence and uniqueness of such an equilibrium price on the positive half-line are addressed in the following Proposition.

Proposition 1 There exists a unique equilibrium price $p_{1}^{*} \in \mathbb{R}^{++}$.

Proof. Denote the left-hand side of equation (14) by $G\left(p_{1}\right)$. We have $\lim _{p_{1} \rightarrow 0^{+}} G\left(p_{1}\right)=-(1-\alpha) \mu A^{\alpha}<0$ and $\lim _{p_{1} \rightarrow+\infty} G\left(p_{1}\right)=+\infty$. Moreover, $G\left(p_{1}\right)$ is continuous and monotonically increasing $\left(G^{\prime}\left(p_{1}\right)>0\right)$. Therefore, there exists a unique $p_{1}^{*} \in(0,+\infty)$ such that $G\left(p_{1}^{*}\right)=0$.

Let us now establish some properties of this equilibrium price.

Proposition 2 The equilibrium price $p_{1}^{*}$

i) increases (resp. decreases) with $\lambda$ if and only if $\gamma_{F}>\gamma_{S}\left(\right.$ resp. $\left.\gamma_{F}<\gamma_{S}\right)$;

ii) decreases with both $\gamma_{F}$ and $\gamma_{S}$;

iii) (a) increases with $\mu$ and (b) decreases with $\sigma^{2}$;

iv) decreases with $S_{0}$.

Proof. The proof makes use of the implicit function theorem. It is detailed in the appendix.

In order to understand the intuition behind these results, let us first define the concept of risk bearing capacity of the market which we denote by $\rho$ :

$$
\rho=\frac{1-\lambda}{\gamma_{F}}+\frac{\lambda}{\gamma_{S}}
$$


The risk bearing capacity of the market is a decreasing function of both agents' degree of risk aversion. It is an increasing (resp. decreasing) function of the share of speculators if and only if their degree of risk aversion is lower (resp. higher) than the one of firms, $\gamma_{S}<\gamma_{F}$ (resp. $\gamma_{S}>\gamma_{F}$ ).

Proposition $2 \mathrm{i}$ ) and ii). Any change in the parameters $\gamma_{F}, \gamma_{S}$ or $\lambda$ which induces a decrease of $\rho$ leads the firms to increase their level of output. This translates into a higher demand for emission permits. $S_{0}$ being fixed, this rises their equilibrium price.

Proposition 2 iii). An increase in the expected value of the productivity parameter $\mu$ leads to a larger expected production and to a higher equilibrium price through the rising demand for permits. $\rho$ being given, an increase in the level of uncertainty $\sigma^{2}$ means that production becomes more risky for the firms. This decreases their demand for permits, which drives down the equilibrium price.

Proposition 2 iv). Permits price is decreasing with the total amount of permits issued.

We now focus on studying the behavior of permits prices. Let $R=p_{2} / p_{1}$ denote the (gross) return earned on permits between the two trading rounds. The following Proposition characterizes expected returns, $E(R)$, as well as their volatility, $V(R)$.

Proposition $3 a$. In equilibrium expected returns are strictly greater than unity, i.e. $E(R)>1$, and, consequently, $x_{1}>0$.

b. Both expected returns and volatility

i) decrease (resp. increase) with $\lambda$ if and only if $\gamma_{F}>\gamma_{S}\left(\right.$ resp. $\left.\gamma_{F}<\gamma_{S}\right)$;

ii) increase with both $\gamma_{F}$ and $\gamma_{S}$;

iii) increase with $\sigma^{2}$;

iv) increases with $S_{0}$.

v) a) expected returns decrease (resp. increase) with $\mu$ if and only if $\alpha<1 / 2$ (resp. $\alpha>1 / 2$ ) and v) b) volatility always decreases with $\mu$.

Proof. The proof makes use of the implicit function theorem. It is detailed in the appendix.

Proposition 3 a. states that expected prices rise through time. In fact, speculators are ready to bear part of the risk by holding the risky asset $\left(x_{1}>0\right)$ provided that they are compensated for that. The compensation takes place through the (strictly positive) difference between $E\left(p_{2}\right)$ and $p_{1}$, i.e., through an expected return greater than one.

As far as Proposition $3 \mathrm{~b}$. is concerned, $E(R)$ and $V(R)$ depend on each of the parameter under consideration $\left(\lambda, \gamma_{F}, \gamma_{S}, \sigma^{2}\right.$ and $\left.S_{0}\right)$ only through $p_{1}$ (except for the dependence of $V(R)$ w.r.t. $\sigma^{2}$ and $E(R)$ w.r.t. $\mu$ ). As $E(R)$ and $V(R)$ are inverse functions of $p_{1}$, their derivatives w.r.t. each 
parameter have the opposite sign of the derivative of $p_{1}$ w.r.t. the same parameter, which is given in Proposition $2 .{ }^{9}$

Then, the comparative statics results hinge on the same reasoning offered for Proposition 2. For example, if the risk bearing capacity of the market decreases (through changes in $\gamma_{F}, \gamma_{S}$ and/or $\lambda$, see i) and ii)), or if the level of uncertainty increases (see iii)), holding permits become more risky and the compensation for holding them necessarily increases. Moreover, as uncertainty rises, the variance of $p_{2}$ increases, and so does the variance of the return.

The analysis of return volatility is of particular interest, given the overall attention devoted to price fluctuations in financial markets by a wide range of agents, including authorities monitoring markets' behavior. Here, we identify determinants of volatility in the emission permit market. While the dependence of volatility on several underlying parameters closely mirrors the results for other asset markets, our analysis has interesting implications: an increase of the risk bearing capacity of the market or a decrease in the level of uncertainty stabilize prices, and vice-versa.

\section{The policy of the agency and the impact of spec- ulators on social welfare}

When defining the optimal amount of permits to be issued and allocated to firms $\left(S_{0}\right)$, the agency balances the social gains from reducing the total amount of emissions with the losses in production due to the constraint on emissions. The present section is devoted to such an analysis.

The objective of the agency is to maximize expected aggregate production of firms, less their consumption of capital and the damage costs due to pollution. It is assumed, for simplicity, that marginal damage costs are constant. To be consistent with the preferences of the agents in the economy, we also allow for risk-aversion (CARA) on the part of the agency as captured by the absolute risk-aversion coefficient $\gamma_{A}$. Hence, recalling that $S_{0}=\int_{0}^{1-\lambda} e_{i} d i$ (by (6)) and $K=\int_{0}^{1-\lambda} k_{i} d i$, the agency objective is defined in terms of the aggregate welfare ${ }^{10}$

$$
\theta K^{\alpha} S_{0}^{1-\alpha}-r K-\delta S_{0}
$$

\footnotetext{
${ }^{9}$ For the dependence of $V(R)$ w.r.t. $\sigma^{2}$ and $E(R)$ w.r.t. $\mu$, one must in addition take into account the direct effect of, respectively, $\sigma^{2}$ and $\mu$.

${ }^{10}$ One interpretation of (15) is as follows. At a macroeconomic level (in a closed economy with no public expenditures), when $\theta$ is interpreted as a shock on the technology, the capital used by the firms is produced by them. Therefore, the price of capital equals the price of output, that is, $r=1$ since the output price has been normalized to 1 . Therefore, aggregate production less aggregate capital corresponds to aggregate consumption. Accordingly, the objective of the agency (15) can be seen as a particular social utility function depending positively on consumption and negatively on pollution.
} 
where $\delta S_{0}$ is the total damage associated with pollution level $S_{0}$. Letting $\mu_{A}(\cdot)$ and $\sigma_{A}^{2}(\cdot)$ denote the first two moments of the aggregate welfare, the problem of the agency can be written -as for the firms and the speculators (see section 1 above)- as follows:

$$
\begin{gathered}
\max _{S_{0}} \mu_{A}\left(S_{0}\right)-\frac{\gamma_{A}}{2} \sigma_{A}^{2}\left(S_{0}\right) \\
\text { subject to eqs. (8), (11), (14) and } S_{0} \geq 0
\end{gathered}
$$

Let $\hat{S}_{0}$ be a solution to the optimization problem (16), and $W\left(\hat{S}_{0}\right)$ be the corresponding welfare, i.e. $W\left(\hat{S}_{0}\right)=\mu_{A}\left(\hat{S}_{0}\right)-\frac{\gamma_{A}}{2} \sigma_{A}^{2}\left(\hat{S}_{0}\right)$. The remainder of the analysis concerns the characterization of a non-negative solution to (16), as well as the properties of the aggregate welfare. The existence and uniqueness of a solution to problem (16) are addressed by the following proposition:

Proposition 4 The optimization problem (16) admits a unique positive maximum $\hat{S}_{0}>0$ for which $W\left(\hat{S}_{0}\right)>0$ if and only if $\delta<\hat{\delta}=\left(\frac{(1-\alpha) \mu}{A^{\alpha}}\right)^{\frac{1}{1-\alpha}}$.

Proof. See the appendix.

In words, a necessary and sufficient condition for the maximum to be positive is that the marginal willingness to pay for the environment is not too big. Indeed, if the marginal damage costs are large, the agency chooses to issue and allocate no emission permits at all, such that production -and therefore pollution- will not take place.

Let us now analyze how an increase in the risk-bearing capacity of the market affects social welfare.

Proposition 5 If $\delta<\hat{\delta}$, then $\frac{d W\left(\hat{S}_{0}\right)}{d \rho}>0$ if and only if $\gamma_{A}<\frac{1}{\rho}$.

Proof. See the appendix.

According to Proposition 5 social welfare exhibits a non-monotonic relationship with the risk-bearing capacity of the market. The intuition behind the above condition is that one has to compare the average market risk aversion (given by $1 / \rho$ ) with the agency's risk aversion.

Finally, one can easily check the intuitive result that the higher the marginal damage $(\delta)$, the lower the social welfare, i.e.

Proposition 6 If $\delta<\hat{\delta}$, then $\frac{d W\left(\hat{S}_{0}\right)}{d \delta}<0$

Proof. See the appendix. 


\section{Discussion}

Three important issues deserve additional comments. The first and the second ones are related to our main results, namely the changes in permits prices (Proposition 3) and the changes in welfare (Proposition 6). The third issue concerns short-selling constraints and the introduction of derivatives.

1. A careful look at existing markets such as the US market for $\mathrm{SO}_{2}$ permits or the European market for $\mathrm{CO}_{2}$ permits reveals that permits prices may significantly fluctuate through time. Of course, numerous elements explain these fluctuations, such as changes in oil or electricity prices, weather, political decisions, etc. ${ }^{11}$ Our results (in particular Proposition 3) suggest that, besides these exogenous shocks, risk aversion and risk hedging behavior may explain part of the price movements observed on markets for emission permits. ${ }^{12}$

Indeed, we have shown that (expected) permits prices tend to rise through time. Although it is well known in the finance literature, this result departs from the existing contributions on transaction costs (see e.g. Stavins (1995)) or intermediation (see e.g. Germain et al. (2004)) in markets for emission permits, which emphasizes the possible existence of a spread (i.e., a difference between the price at which permits are sold and the price at which permits are purchased). Here, we observe an intertemporal spread, i.e., a situation in which expected permits prices change through time. Moreover, we have also shown that the volatility of the prices is influenced by the presence of speculators and, more generally, by the risk bearing capacity of the market. An increase in the risk bearing capacity tends to stabilize prices, and vice-versa.

2. Classical analyses of the tradable emission permits instrument do not account for the participation of speculators on the market. The main policy implications of our analysis depend on the degree of risk aversion of the agency w.r.t. the one of firms and speculators. If an increase in the number of speculators increases the risk bearing capacity of the market, ${ }^{13}$ then by Proposition 5 institutional rules should favor the presence of speculators on markets for emission permits (by contrast with the situation where only polluting firms are present on the market). However, allowing speculators to operate on the emission permits market should be granted only to a certain extent, i.e. only as long as the agency's risk tolerance remains greater than the market risk bearing capacity.

3. Another policy-oriented issue is the extent to which short-selling of emission permits is likely to take place. As shown in Proposition 3, firms

\footnotetext{
${ }^{11}$ On this topic, see for instance Albrecht et al. (2004) for the US $\mathrm{SO}_{2}$ market and Convery and Redmond (2005) for the $\mathrm{EU} \mathrm{CO}_{2}$ market.

${ }^{12}$ Some authors, including Zhao (2003), have dealt with the consequences of a change in the permits price. Here, we give a possible explanation for such changes.

${ }^{13}$ This would occur whenever firms are more risk-averse than speculators, see section 1.
} 
find it optimal to unload some or the whole stock of permits to speculators during the first trading round. Once uncertainty is resolved, i.e. during the second trading period, firms buy back permits and use them in the production process. The (expected) price differential compensates speculators for bearing the risk of holding permits during the first period. In some situations, typically when their degree of risk aversion is low, speculators might be willing to hold more than the total amount of permits available in the economy. One may therefore wonder if the total amount of permits purchased by speculators should not be constrained by the total amount of permits allocated by the agency (i.e., $x_{1} \leq S_{0} / \lambda$ ).

Exactly as on financial markets, such a constraint is not likely to be relevant. In fact, institutions can be designed in order to allow the agents to hold (temporarily) a negative amount of emission permits in their account, i.e., to allow for short selling. ${ }^{14}$ Otherwise, the introduction of forward contracts (with cash delivery) may play the same role in ruling out shortselling constraints. A long (resp. short) forward contract specifies the future date and the price at which one agent will sell (resp. buy), say, one permit. The introduction of such contracts in our model is straightforward. The first period is devoted to the forward trading (instead of being a spot market). $x_{1 j}$ is the number of forwards sold by speculator $j$ (in period 1) and $x_{2 j}=-x_{1 j}$ is the delivery of the permits (in period 2). $p_{2}$ is the price of the permits on the spot market (in period 2). If contracts allow for cash delivery (as opposed to physical delivery, i.e., in terms of emission permits), speculators may purchase an amount of permits that is larger than the amount of permits available in the economy.

\section{Conclusion}

We have analyzed the impact of speculators on the emission permits market when agents are risk-averse. Our main results are the following. First, the expected permits price increases through time, so that there is some room for risk hedging by speculators. Second, an increase in the risk bearing capacity of the market (due for instance to an increase in the number of speculators or a decrease in the risk aversion of firms or speculators) rises expected social welfare up to a certain point depending on the agency's risk tolerance.

Although the determination of an endogenous number of speculators in the market is of interest, we do not tackle this issue here and we leave it for future research. A second extension, which could help to understand more comprehensively the role of speculators on markets for emission permits, would consist in introducing feedback (noise) traders à la De Long

\footnotetext{
${ }^{14}$ For instance, on the recently launched European market for CO2 permits, shortselling is possible.
} 
et al. (1990). These authors focus on speculators who make their trading decision by simply extrapolating past prices. They show that the presence of such traders may cause the emergence of a bubble. A third interesting extension would be to allow for informational asymmetries between the different types of agents. For instance, one could consider that, by performing market analyses, speculators are better informed than firms about possible macroeconomic shocks.

\section{References}

Albrecht, J., T. Verbeke and M. De Clercq (2004), "Informational efficiency of the US $\mathrm{SO}_{2}$ permit market", mimeo, University of Gent W.P. 2004/250.

Baldursson, F. and N-H. von der Fehr (2004), "Price volatility and risk exposure: on market-based environmental policy instruments", Journal of Environmental Economics and Management 48: 682-704.

Bernardo, A. and I. Welch (2004), "Liquidity and financial market runs", Quarterly Journal of Economics 119(1): 135-158.

Convery, F. and L. Redmond (2005), "The Evolution of the European Market in CO2 Allowances - a note", mimeo, paper presented at the 2005 EAERE conference, Bremen, June.

De Long, J., A. Shleifer, L. Summers and R. Waldmann (1990), "Positive feedback investment strategies and destabilizing rational speculation", Journal of Finance 45: 375-395

Germain, M., S. Lovo and V. van Steenberghe (2004a), "De l'importance de la microstructure des marchés de permis de polluer", Annales d'Economie et de Statistique 74: 177-208.

Germain, M., V. van Steenberghe and A. Magnus (2004b), "Optimal environmental policy under bankable emission permits: taking the market microstructure into account", Journal of Public Economic Theory 6: 737-757.

Lintner, J. (1969), "The Aggregation of Investor's Diverse Judgements and Preferences in Purely Competitive Security Markets", Journal of Financial and Quantitative Analysis 4: 347-400.

Sandmo, A. (1971), "On the theory of the competitive firm under uncertainty", The American Economic Review 61 (1): 65-73. 
Schmalensee, R., P. Joskow, A. Ellerman, J. Montero, and E. Bailey (1998),"An Interim Evaluation of Sulfur Dioxide Emissions Trading", Journal of Economic Perspectives, 12(3): 53-68, summer.

Stavins, R. (1995), "Transaction costs and tradable permits", Journal of Environmental Economics and Management 29(2): 133-148.

Stavins, R. (2003), "Experience with market-based environmental policy instruments", in K.-G. Mäler and J. Vincent, Handbook of environmental economics. Volume I: Environmental degradation and institutional responses, Elsevier.

Vives, X. (1984), "Duopoly information equilibrium: Cournot and Bertrand", Journal of Economic Theory, 34: 71-94.

Zhao, J. (2003), "Irreversible abatement investment under cost uncertainties: tradable emission permits and emissions charges", Journal of Public Economics 87(12): 2765-2789.

\section{Appendix}

Proof (Proposition 2). Let $\Omega$ be the set of underlying parameters, i.e. $\Omega=\left(\lambda, \gamma_{S}, \gamma_{F}, \mu, \sigma^{2}, r, S_{0}\right)$, and $\omega_{i}$ be a given parameter in $\Omega$. Moreover let $G\left(p_{1}, \Omega\right)$ denote the LHS in equation (14). We are interested in evaluating how the underlying parameters affect the equilibrium price $p_{1}^{*}=p(\Omega)$ defined by $G\left(p_{1}^{*}, \Omega\right)=0$. The implicit function theorem yields

$$
\frac{\partial p_{1}^{*}}{\partial \omega_{i}}(\Omega)=-\frac{\partial G\left(p_{1}^{*}, \Omega\right) / \partial \omega_{i}}{\partial G\left(p_{1}^{*}, \Omega\right) / \partial p_{1}}
$$

Recall from the proof of Proposition 1 that $\partial G\left(p_{1}^{*}, \Omega\right) / \partial p_{1}>0$. Computing the partial derivatives of $G\left(p_{1}, \Omega\right)$ with respect to the elements in $\Omega$ yields $\frac{\partial G\left(p_{1}^{*}, \Omega\right)}{\partial \gamma_{S}}>0, \frac{\partial G\left(p_{1}^{*}, \Omega\right)}{\partial \gamma_{F}}>0, \frac{\partial G\left(p_{1}^{*}, \Omega\right)}{\partial \mu}<0, \frac{\partial G\left(p_{1}^{*}, \Omega\right)}{\partial \sigma^{2}}>0$ and $\frac{\partial G\left(p_{1}^{*}, \Omega\right)}{\partial S_{0}}>0$ thus establishing the comparative statics results $(i i)-(i v)$. Taking the partial derivative of $G\left(p_{1}, \Omega\right)$ with respect to the fraction of speculators, $\lambda$, gives

$$
\operatorname{sgn}\left(\frac{\partial G\left(p_{1}^{*}, \Omega\right)}{\partial \lambda}\right)=\left\{\begin{array}{cc}
-1 & \text { if } \gamma_{F}>\gamma_{S} \\
0 & \text { if } \gamma_{F}=\gamma_{S} \\
+1 & \text { otherwise }
\end{array}\right.
$$

and claim $(i)$ follows.

Proof (Proposition 3). Checking that $E(R)>1$ is equivalent to

$$
E\left(p_{2}\right)-p_{1}=\frac{(1-\alpha) \mu p_{1}^{\alpha}}{A^{\alpha}}-p_{1}>0 .
$$


Rearranging this expression for the expected price differential yields

$$
E\left(p_{2}\right)-p_{1}=\left(\frac{p_{1}}{A^{2}}\right)^{\alpha}\left[(1-\alpha) \mu A^{\alpha}-A^{2 \alpha} p_{1}^{1-\alpha}\right]
$$

In equilibrium $(1-\alpha) \mu A^{\alpha}-A^{2 \alpha} p^{1-\alpha}=(1-\alpha) B S_{0} p^{\alpha}$, which gives $E\left(p_{2}\right)-$ $p_{1}>0 . E\left(p_{2}\right)-p_{1}>0$.

Combining (5) and (12) and rearranging terms leads to

$$
x_{1}=\frac{\Delta^{2 \alpha}}{\gamma_{S} \sigma^{2}(1-\alpha)^{2}}\left[E\left(p_{2}\right)-p_{1}\right]
$$

such that $E(R)>1$ yields $x_{1}>0$.

Let $\Omega$ and $\omega_{i}$ be defined along the same lines as in the proof of Proposition 2. From the expression for $p_{2}$ in eq. (5) one has

$$
E(R)=E\left(R\left(p_{1}, \Omega\right)\right)=\frac{(1-\alpha) \mu}{A^{\alpha} p^{1-\alpha}} \quad \text { and } \quad V(R)=V\left(R\left(p_{1}, \Omega\right)\right)=\frac{(1-\alpha)^{2} \sigma^{2}}{A^{2 \alpha} p^{2(1-\alpha)}}
$$

Therefore

$$
\frac{\partial E(R)}{\partial \omega_{i}}=-\frac{(1-\alpha)^{2} \mu}{A^{\alpha} p_{1}^{2-\alpha}} \frac{\partial p_{1}}{\partial \omega_{i}} \quad \text { for } \omega_{i}=\left\{\lambda, \gamma_{S}, \gamma_{F}, \sigma^{2}, S_{0}\right\}
$$

and

$$
\frac{\partial V(R)}{\partial \omega_{i}}=-2 \frac{(1-\alpha)^{3} \sigma^{2}}{A^{2 \alpha} p^{3-2 \alpha}} \frac{\partial p_{1}}{\partial \omega_{i}} \quad \text { for } \omega_{i}=\left\{\lambda, \gamma_{S}, \gamma_{F}, \mu, S_{0}\right\}
$$

Making use of these expressions together with the comparative statics analysis in Proposition 2 yields results $i, i i$ and $i v$ and the claims that expected returns increase with $\sigma^{2}$ (see part iii) while volatility decreases with $\mu$. Moreover returns volatility increases with $\sigma^{2}$ since

$$
\frac{\partial V(R)}{\partial \sigma^{2}}=\left(\frac{1-\alpha}{A^{\alpha}}\right)^{2}\left(-2 \frac{(1-\alpha) \sigma^{2}}{p^{3-2 \alpha}} \frac{\partial p_{1}}{\partial \sigma^{2}}+\frac{1}{p^{2(1-\alpha)}}\right)
$$

and $\frac{\partial p_{1}}{\partial \sigma^{2}}<0$ from Proposition 2 - part $i i i$-b. Finally in order to complete the Proof consider

$$
\frac{\partial E(R)}{\partial \mu}=\frac{1-\alpha}{A^{\alpha}}\left(-\frac{(1-\alpha) \mu}{p_{1}^{2-\alpha}} \frac{\partial p_{1}}{\partial \mu}+\frac{1}{p^{1-\alpha}}\right)
$$

Substituting for $\frac{\partial p_{1}}{\partial \mu}$ in the latter and considering the market equilibrium condition (14) gives

$$
\frac{\partial E(R)}{\partial \mu}=-\frac{(1-\alpha)(1-2 \alpha) B S_{0}}{A^{\alpha} p_{1}^{2(1-\alpha)}\left(A^{2 \alpha} p_{1}^{-\alpha}+\alpha B S_{0} p_{1}^{\alpha-1}\right)}
$$

such that $\operatorname{sgn}\left(\frac{\partial E(R)}{\partial \mu}\right)=\operatorname{sgn}(2 \alpha-1)$. 
Proof (Proposition 4). The proof consists of three steps. We first reduce the constrained optimization defined in (16) to an equivalent problem keeping into account the equilibrium constraints (11), (14) and $S_{0} \geq 0$. In the second step we determine the necessary and sufficient conditions under which the welfare function is strictly positive. This way, we are able to give conditions for which the problem of the agency admits at least one positive maximum -yielding a strictly positive optimal value of the aggregate welfare. Finally, we show that the maximum is unique.

Step 1: alternative formulation for the maximization problem

Let $W\left(S_{0}, \rho\right)=\mu_{A}-\frac{\gamma_{A}}{2} \sigma_{A}^{2}$ be the objective function in (16) to be optimized with respect to $S_{0}$. Rearranging eq. (14) gives

$$
S_{0}=\frac{\rho}{\sigma^{2}}\left(\frac{A}{p}\right)^{\alpha}\left(\mu-\frac{A^{\alpha} p^{1-\alpha}}{1-\alpha}\right)
$$

The non-negativity constraint for the initial amount of permits, $S_{0} \geq 0$, is therefore equivalent to require that

$$
\mu-\frac{A^{\alpha} p^{1-\alpha}}{1-\alpha} \geq 0
$$

Using eq. (17) together with eq. (11) yields the following expression for the aggregate capital

$$
K=\frac{\rho}{\sigma^{2}}\left(\frac{p}{A}\right)^{1-\alpha}\left(\mu-\frac{A^{\alpha} p^{1-\alpha}}{1-\alpha}\right)
$$

Note that eqs. (17-19) imply that $K^{\alpha} S_{0}^{1-\alpha}=\frac{\rho}{\sigma^{2}}\left(\mu-\frac{A^{\alpha} p^{1-\alpha}}{1-\alpha}\right)$ such that the maximization problem (16) reduces to the following

$$
\begin{gathered}
\max _{p>0} W(p, \rho)=\frac{\rho}{\sigma^{2}}\left(\mu-\frac{A^{\alpha} p^{1-\alpha}}{1-\alpha}\right)\left(\mu(1-C(\rho))+\frac{(C(\rho)-\alpha) A^{\alpha} p^{1-\alpha}}{1-\alpha}-\frac{A^{\alpha} \delta}{p^{\alpha}}\right) \\
\text { s.t. } \mu-\frac{A^{\alpha} p^{1-\alpha}}{1-\alpha} \geq 0
\end{gathered}
$$

where we set $C(\rho)=\frac{\gamma_{A} \rho}{2}$. We finally rewrite the problem (20) operating a change in variables by defining

$$
x=\mu-\frac{A^{\alpha} p^{1-\alpha}}{1-\alpha}
$$

Therefore the second term in brackets in the objective function in (20) becomes

$$
G(x, \rho)=\mu(1-\alpha)+(\alpha-C(\rho)) x-\frac{D}{(\mu-x)^{\frac{\alpha}{1-\alpha}}}
$$


where we set

$$
D=\delta\left(\frac{A}{1-\alpha}\right)^{\frac{\alpha}{1-\alpha}}
$$

Finally note that $p>0$ is equivalent to $x<\mu$ such that the optimization (23) can be rewritten in the following way

$$
\max _{x \in[0, \mu)} W(x, \rho)=\frac{\rho}{\sigma^{2}} x G(x, \rho)
$$

where $x$ and $G(\cdot)$ are defined in (21) and (22).

\section{Step 2: positiveness of $W$}

We are interested in determining conditions for which the objective function in (23) takes strictly positive values. In fact the agency can always choose $x=0$ and get $W(0, \rho)=0$. So we are interested in the problem with strict inequality, i.e. $x>0$ (which corresponds to $S_{0}>0$ ). By taking the appropriate limits, note that the function $G(x, \rho)$ evaluated at $x=0$ does not depend on $\rho$

$$
G(0)=(1-\alpha) \mu-\frac{D}{\mu^{\frac{\alpha}{1-\alpha}}}
$$

and diverges to $-\infty$ as $x$ approaches the upper limit $\mu$. Taking the first and second derivative with respect to $x$ yields:

$$
\begin{aligned}
G_{x}(x, \rho) & =\alpha-C(\rho)-\frac{\alpha}{1-\alpha} \frac{D}{(\mu-x)^{\frac{1}{1-\alpha}}} \\
G_{x x}(x, \rho) & =-\frac{\alpha}{(1-\alpha)^{2}} \frac{D}{(\mu-x)^{\frac{2-\alpha}{1-\alpha}}}
\end{aligned}
$$

Note that according to the latter derivative the function $G(x, \rho)$ is strictly concave over $(0, \mu)$. One can easily check that $G(0)>0$ if and only if

$$
\delta<\hat{\delta}=\left[\frac{(1-\alpha) \mu}{A^{\alpha}}\right]^{\frac{1}{1-\alpha}} .
$$

On the other hand, $\delta \geq \hat{\delta}$ is sufficient for $G_{x}(0, \rho)<0$. In such a case, given the global concavity of $G$, it is then impossible that $W$ has a positive maximum somewhere in $(0, \mu)$. Thus it is necessary that $\delta<\hat{\delta}$. Condition (25) is also sufficient. Indeed, $\delta<\hat{\delta}$ implies that $W_{x}(0, \rho)=\frac{\rho}{\sigma^{2}} G(0)>0$. As $W(0, \rho)=0$, welfare $W$ is strictly positive on a subset of $(0, \mu)$.

Step 3: existence of a global maximum 
The first two derivatives of the welfare function $W(x, \rho)$ are

$$
\begin{aligned}
W_{x}(x, \rho) & =\frac{\rho}{\sigma^{2}}\left[G(x, \rho)+x G_{x}(x, \rho)\right] \\
W_{x, x}(x, \rho) & =\frac{\rho}{\sigma^{2}}\left[2 G_{x}(x, \rho)+x G_{x x}(x, \rho)\right]
\end{aligned}
$$

From Step 2 above, we know that there exists an admissible interval over which the welfare function is strictly positive if and only if $\delta<\hat{\delta}$. Assuming that the latter condition is met, since $W$ is continuous and differentiable on $[0, \mu)$ a candidate maximum for the welfare function is characterized by $W_{x}(\check{x}, \rho)=0$ where $\check{x} \in(0, \mu)$ is such that $W(\check{x}, \rho)>0$. From (26) one has $G_{x}(\check{x}, \rho)=-G(\check{x}, \rho) / \check{x}$ which is strictly negative since $G(\check{x}, \rho)>0$. It follows that $\check{x}$ is indeed a local maximum since $W_{x, x}(\check{x}, \rho)<0$ by the strict concavity of the function $G(\cdot)$ (see Step 2). For the same reason, there cannot be any local minima. Thus there cannot be several local maxima and $\check{x}$ is the unique global maximum.

Proof (Proposition 5). Consider the agency's optimization problem as given in $(23)$ and let $\hat{x} \in(0, \mu)$ be the unique maximum. By the Envelope Theorem

$$
\frac{d W(\hat{x}, \rho)}{d \rho}=W_{\rho}(\hat{x}, \rho)=\frac{\hat{x}}{\sigma^{2}}\left[G(\hat{x}, \rho)+\rho G_{\rho}(\hat{x}, \rho)\right]
$$

From eq. (22) one has $G_{\rho}(\hat{x}, \rho)=-\frac{\gamma_{A} \hat{x}}{2}$, while (26) yields $G(\hat{x}, \rho)=$ $-\hat{x} G_{x}(\hat{x}, \rho)$ so that

$$
W_{\rho}(\hat{x}, \rho)=-\frac{\hat{x}^{2}}{\sigma^{2}}\left[G_{x}(\hat{x}, \rho)+\frac{\rho \gamma_{A}}{2}\right]
$$

Using the expression for $G_{x}(\cdot)$ (see eq. (24)) and rearranging gives

$$
\operatorname{sgn}\left(W_{\rho}(\hat{x}, \rho)\right)=\operatorname{sgn}\left(\frac{D}{(1-\alpha)(\mu-\hat{x})^{\frac{1}{1-\alpha}}}-1\right)
$$

Now note that the condition for the global maximum, i.e. $G(\hat{x}, \rho)+\hat{x} G_{x}(\hat{x}, \rho)=$ 0 , yields

$$
(1-\alpha) \mu+2(\alpha-C(\rho)) \hat{x}=\frac{D((1-\alpha) \mu-(1-2 \alpha) \hat{x})}{(1-\alpha)(\mu-\hat{x})^{\frac{1}{1-\alpha}}}
$$

such that

$$
\begin{aligned}
\operatorname{sgn}\left(W_{\rho}(\hat{x}, \rho)\right) & =\operatorname{sgn}((1-2 \alpha) x+2(\alpha-C(\rho)) x)= \\
& =\operatorname{sgn}\left(1-\gamma_{A} \rho\right)
\end{aligned}
$$

which gives the result in Proposition 5. 
Proof (Proposition 6). Consider the agency's optimization problem given by (23). By the Envelope Theorem:

$$
\frac{d W(\hat{x}, \delta)}{d \delta}=W_{\delta}(\hat{x}, \delta)=-\frac{\rho}{\sigma^{2}} x\left(\frac{A}{(1-\alpha)(\mu-\hat{x})}\right)^{\frac{\alpha}{1-\alpha}}<0
$$


Département des Sciences Économiques de l'Université catholique de Louvain

Institut de Recherches Économiques et Sociales

Place Montesquieu, 3

1348 Louvain-la-Neuve, Belgique 